\title{
Regimen Used to Treat Chronic Myeloid Leukemia
}

National Cancer Institute

\section{Source}

National Cancer Institute. Regimen Used to Treat Chronic Myeloid Leukemia. NCI

Thesaurus. Code C159441.

Any regimen that can be used for the treatment of chronic myeloid leukemia (CML). 